\title{
ÍNDICES DE QUALIDADE DE VIDA URBANA DE NATAL-RN
}

\author{
M. C. C. ARAÚJO $0^{1^{*}}$ e G. A. CÂNDIDO ${ }^{2}$ \\ ${ }^{1}$ Instituto Federal de Educação, Ciência e Tecnologia do Rio Grande do Norte - IFRN \\ ${ }^{2}$ Universidade Federal de Campina Grande - UFCG \\ cristina.cavalcanti@ifrn.edu.br* \\ Artigo submetido em março/2015 e aceito em março/2015 \\ DOI: 10.15628/geoconexoes.2015.2836
}

\section{RESUMO}

A (in)sustentabilidade nas cidades, ocasionada pela urbanização, compromete a qualidade de vida urbana, evidenciada pela distribuição e o acesso desigual aos bens e serviços de infraestrutura urbana. Este artigo apresenta discussões sobre a temática da sustentabilidade urbana ao estabelecer o Índice de Qualidade de Vida urbana de Natal-RN. A pesquisa se baseou em estudos bibliográficos e documentais. A avaliação dos níveis de qualidade de vida urbana de Natal ocorreu por meio da definição de variáveis e indicadores, subsidiados por dados secundários, os quais foram transformados em índices e organizados em níveis de qualidade. Organizou-se o ranking dos bairros, por meio da mensuração da oferta de serviços e recursos urbanos, estabelecendo-se o nível de qualidade de vida urbana de Natal, com vistas à sustentabilidade da cidade. Conclui-se que, nas áreas onde ocorreu a recente expansão urbana de Natal, encontram-se os piores Índices de Qualidade de Vida Urbana-IQVU.

PALAVRAS-CHAVE: expansão urbana, (in)sustentabilidade urbana, qualidade de vida, indicador.

\section{SUSTAINABILITY AND QUALIT OF URBAN LIFE IN THE CITY NATAL-RN}

\begin{abstract}
The (un)sustainability in the cities, caused by urbanization, compromises the quality of urban life, evidenced by the distribution and unequal access to goods and services of urban infrastructure. This paper presents discussions on the theme of urban sustainability when it's established the quality of urban life Natal-RN. The research was based on bibliographic and documentary studies. The assessment of urban life quality levels of Natal occurred through the definition of
\end{abstract}

variables and indicators, subsidized by secondary data, which were transformed into indices and organized into levels of quality. The ranking of districts was organized through the measure of supplies of urban services and resources, establishing the level of urban life quality of Natal for sustainability of the city. We conclude that, in areas where the recent urban expansion in Natal occurred, are found the worst Urban Life Quality Indices-ULQI.

KEYWORDS: urban expansion, urban (un)sustainability, quality of life, indicator. 


\section{INTRODUÇÃO}

As recentes discussões sobre sustentabilidade evidenciaram a necessidade de seu monitoramento e a definição de instrumentos de avaliação. Diversas formas foram estudadas e trazidas à tona por seus pesquisadores ou grupos de pesquisas. No entanto, entende-se que a qualidade de vida urbana é um indicador importante para avaliação da sustentabilidade urbana. Nesse sentido, enveredar por meio de um estudo empírico sobre a qualidade de vida urbana traz à tona a contribuição ao se somar às discussões sobre a sustentabilidade.

A cidade de Natal, capital do Rio Grande do Norte, foi a escolhida como recorte espacial deste trabalho. Isso se deve ao fato da evidência empírica do crescimento urbano e da urbanização da qual a cidade vem passando nos últimos tempos. O crescimento do sítio urbano se deu em todas as direções da cidade, provocando transbordamentos para municípios circunvizinhos. Esse quadro de referência trouxe incertezas quanto à sustentabilidade da cidade e, portanto, da qualidade de vida urbana.

Nesse sentido, procurou-se ampliar e avançar as discussões sobre qualidade de vida de Natal-RN ao incorporar, variáveis e indicadores de dimensões (ambiental, social e econômica) para a definição do IQVU de Natal. Aqui, procurou-se articular o processo de expansão urbana e o comprometimento da qualidade de vida urbana, observando-se os aspectos materiais, coletivos e objetivos, por meio de indicadores expressos por dados secundários.

Além disso, fez-se a opção de se estabelecer os níveis espaciais de qualidade de vida a partir dos bairros de Natal-RN por compreender que estes melhor refletem a configuração urbana e espacial do município contribuindo no acompanhamento temporal da evolução urbana local, o que considera-se como a contribuição deste trabalho.

Em suma, a relevância deste trabalho está, também, em mensurar e estabelecer os níveis espaciais de oferta de serviços e recursos urbanos que serão de extrema importância para a identificação e o monitoramento da qualidade de vida urbana de Natal-RN.

Considerando-se esse quadro de referência para a proposição da pesquisa, partiu-se da premissa de que o processo de expansão urbana de Natal-RN, ocorrido na contemporaneidade, deu-se por meio de forte pressão ambiental e em condições socioeconômicas desiguais, contribuindo para a distribuição desigual da oferta de serviços de infraestrutura urbana, que tem comprometido a qualidade de vida urbana.

Assim, o estudo objetivou avaliar os níveis de qualidade de vida urbana de Natal-RN, a partir da definição de indicadores e índices que possibilitaram a mensuração de oferta de serviços e recursos urbanos, com vistas à sustentabilidade da cidade.

\section{LOCALIZAÇÃO DA ÁREA DE ESTUDO}

O município de Natal (Figura 1), capital do estado do Rio Grande do Norte (RN), e área objeto do presente estudo, está situado na zona costeira do Brasil, na região Nordeste do país e na mesorregião Leste Potiguar. 

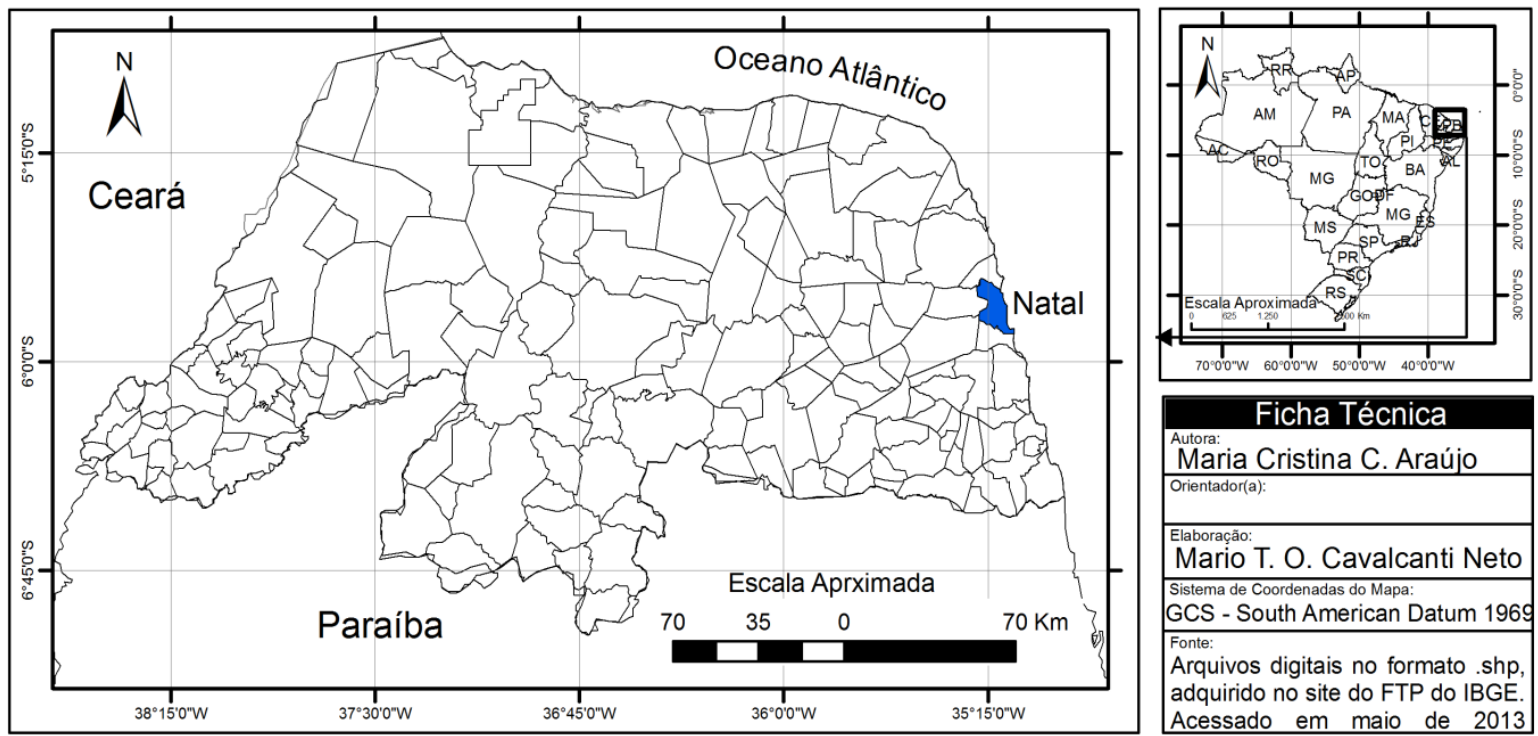

Figura 1 - Localização de Natal-RN no Rio Grande do Norte

Sua área territorial, de $167,263 \mathrm{~km}^{2}$, encontra-se situada no paralelo de 50 47'42" de latitude sul e o meridiano de 3512'34" a oeste de Greenwich (NATAL, 2010b). Abriga atualmente 803.739 habitantes, cuja taxa de população urbana hoje chega a 100\%, com 177.317 domicílios, distribuídos nas quatro zonas administrativas: Oeste, Lestes, Sul e Norte.

\subsection{Qualidade de Vida Urbana: algumas considerações}

A grande e crescente densidade populacional nas cidades compromete o acesso à infraestrutura e serviços urbanos e a outros fatores promotores da qualidade de vida. Assim, crescem os conflitos sociais, a degradação ambiental e os serviços básicos entram em colapso (DANKO; LOURENÇO, 2007). Nesse sentido, Rogers (2008, p. 69) aponta para a necessidade de cidades compactas e justas, em que seja possível "uma adaptação entre direitos particulares e responsabilidades públicas". Dessa maneira, a criação de espaços multifuncionais deve constituir a espinha dorsal das políticas públicas, visando à qualidade de vida urbana sob o viés da sustentabilidade.

Jofré (2009) argumenta que é quase improvável conseguir alcançar cidades sustentáveis. Contudo, o mesmo autor aponta que algo de positivo pode ser feito para atuar na qualidade de vida dos habitantes da cidade. Ainda, Gomes e Dinis (2002), Danko e Lourenço (2007) indicam para um trio que é imperativo no sentido de se conseguir a sustentabilidade e a qualidade de vida urbana, são eles: o econômico, o social e o ambiental. Logo, para haver uma cidade com qualidade de vida para seus habitantes, todas essas dimensões devem ser levadas em consideração de forma integrada.

Segundo Bacha et al. (2010), o progresso, numa sociedade sustentável, pode ser medida pela qualidade de vida. Isso porque, diante do contínuo processo de urbanização da humanidade, faz-se necessária uma urbanização sustentável, isto é, que observe os aspectos ambientais, sociais, econômicos e de governança.

Entre os trabalhos sobre qualidade de vida, destacam-se os desenvolvidos por Haddad Filho para a cidade de Santos; Vitte et al. para a cidade de Santo André; Santos e Martins (2002) para a cidade do Porto, em Portugal; Leite (2009) para Portugal; os desenvolvidos por Nuvolati 
(2002), na Itália; e os desenvolvidos nas universidades do Paraná, por Nahas; por Kran e Ferreira (2006), em Palmas; os trabalhos desenvolvidos em Belo Horizonte, para determinar o IQVU local, por Nahas (2005); e os estudos desenvolvidos pelo Instituto Pólis, dentre outros. No entanto, "as concepções metodológicas diferem em termos de apresentar contextos e objetivos singulares, com complexidades e interesses diversos" (SILVA, 2011, p. 47).

Nuvolati (2002) afirma que a cidade é o local ideal para se pesquisar sobre a qualidade de vida, por ser uma área territorial onde os conflitos e as contradições estão quase sempre latentes. Já Gomes e Dinis (2006, p.1) apontam a dimensão urbana como de grande importância para "a compreensão dos padrões de desenvolvimento socioeconômico, desempenhando um papel igualmente importante na compreensão dos níveis de qualidade de vida e das condições gerais de sustentabilidade do ambiente". Isso se deve ao fato de ser nas cidades lócus da concentração populacional, portanto, onde emergem as fragilidades sociais e ambientais.

Dessa forma, observa-se a necessária relação entre distribuição de renda e equidade no acesso aos serviços urbanos como essenciais para a efetivação da cidadania (LEITE, 2009; NAHAS, 2005; SILVA et al., 2010; MENDONÇA; 2006), conforme já foi pontuado anteriormente.

Mendonça (op cit., p. 14) complementa ainda, ao destacar a impossibilidade de dissociar esses aspectos, que "a oferta é esvaziada se não há possibilidade de efetivo acesso (ou é injusta se este é desigual), e o acesso só é pertinente na hipótese da existência da oferta". Destarte, deve-se buscar o ponto de equilibro entre oferta e possibilidade de acesso.

Nessa mesma linha de raciocínio, Nahas (2005, p. 135) destaca que o conceito de qualidade de vida vincula-se "[...] à noção de equidade na distribuição e acesso da população a 'bens de cidadania' e à noção de qualidade ambiental visando ao desenvolvimento sustentável" [grifo da autora]. Por conseguinte, envolve o conceito de equidade de acesso aos bens e serviços urbanos ou evidencia a desigualdade de acesso.

Corroborando com essa ideia, Silva (2011, p. 50) assevera que "a noção de qualidade de vida envolve duas grandes questões: a qualidade e a democratização dos acessos às condições de preservação do homem, da natureza e do meio ambiente". Ademais, envolve ainda a "possibilidade de melhor redistribuição - e usufruto - da riqueza social e tecnológica aos cidadãos de uma comunidade" (SPOSATI, 2000, p. 27). Assim, novamente fica evidente a noção de qualidade de vida associada à equidade de acesso social, econômico e ambiental. Nesse sentido, aponta-se para a necessidade de estudos que quantifiquem a Qualidade de Vida Urbana com vistas à gestão e à sustentabilidade urbana.

A avaliação da qualidade de vida urbana compreende diversos aspectos que podem ser materiais e imateriais, objetivos e subjetivos, individuais e coletivos (SANTOS; MARTINS, 2002; NUVOLLATI, 2006; LEITE, 2009).

Neste trabalho, entende-se que o conceito de qualidade de vida deve integrar a noção de desenvolvimento humano e a de sustentabilidade; logo, permear variáveis ambientais e sociais. Nesse sentido, considera-se que, para a mensuração da qualidade de vida urbana, três elementos são essenciais: o dimensionamento da equidade de acesso da população aos bens e recursos urbanos, a avaliação da qualidade ambiental e elementos para a discussão sobre a sustentabilidade (NAHAS et al., 2006, p.2-3). 
Portanto, é uma concepção focada na equidade de acesso e na qualidade ambiental, tendo como ênfase no ambiente urbano. Neste trabalho, dar-se-á destaque ao dimensionamento da equidade no acesso aos bens e serviços urbanos, conforme se explicitará na seção material $e$ métodos.

Assim sendo, qualidade de vida urbana passa por várias dimensões, incluindo o acesso democrático da gestão dos recursos em serviços, equipamentos e bens; direito à qualidade requer possibilitar aos habitantes da cidade seus direitos atendidos.

Outra proposta para dimensionar a qualidade de vida urbana é a apresentada por Santos e Martins (2002) para a cidade do Porto, em Portugal. Os autores alertam que "a condição urbana caracteriza-se por uma grande heterogeneidade de usos e ocupações do solo e por uma ampla diversidade funcional”. (SANTOS, MARTINS, 2002, p. 9). Logo, é necessário avaliar e calcular as variáveis como forma de se estabelecer as diferenciações no espaço urbano. Os autores destacam a necessidade de parcerias pública e privada para o fornecimento e a alimentação das informações fundamentais para o estabelecimento do índice de Qualidade de vida.

Para a proposição de um estudo sobre qualidade de vida urbana, Mendonça (2006) frisa que nas discussões sobre a gestão urbana voltada para a inclusão social e territorial, devem-se observar os princípios de universalidade, de equidade, de sustentabilidade e de gestão democrática. Assim, aponta para grupos temáticos como variáveis para a medição da qualidade de vida, tais como: habitação, infraestrutura e mobilidade; formas de organização urbana e ambiental; e capacidade de gestão pública. Portanto, apesar de apontar algumas variáveis diferentes das propostas por outros autores, o autor corrobora com a concepção da qualidade de vida associada com a equidade de acesso e, dessa forma, de cidadania. Afirma ainda que as localidades que exercem centralidades necessitam de determinados recursos e serviços urbanos, evidenciando que a questão regional interfere na avaliação da qualidade de vida.

Kran e Ferreira (2006) ressaltam a necessidade de ampliação das variáveis na análise e mensuração da qualidade de vida. Desse modo, ao desenvolverem estudos sobre a qualidade de vida urbana de Palmas, no Tocantins, optaram por fazer através de indicadores habitacionais (conforto domiciliar) e ambientais urbanos (qualidade ambiental urbana). Os autores destacam que a moradia é um dos mais importantes elementos da qualidade de vida urbana, sendo influência na qualidade do ambiente urbano.

Nuvolotti (2002), em sua pesquisa sobre qualidade de vida na Itália, salienta a utilização desse conceito em diversas áreas das ciências, apontando ainda a falta de consonância entre elas. Todavia, o autor destaca a origem das discussões acerca da qualidade de vida e a associa ao grau de satisfação das necessidades individuais e coletivas.

A partir das concepções apresentadas, depreende-se de forma sintética que o entendimento de qualidade de vida envolve várias dimensões; pode (e deve) ser mensurada e avaliada a partir de aspectos objetivos e subjetivos, individuais e coletivos e, também, a partir de dados quantitativos e qualitativos. Destarte, envolvendo assim a concepção de cidade sustentável, tendo como condicionante básico a sua capacidade de atender às necessidades da população de forma equitativa, proporcionando uma maior qualidade de vida urbana. 


\section{MATERIAIS E MÉTODOS}

As diversas pesquisas sobre a qualidade de vida, tanto nacionais como internacionais, apontam que ela deve ser analisada levando-se em consideração aspectos objetivos e subjetivos, em que "[...] as medidas objectivas compreendem aspectos da vida tangíveis, diretamente verificáveis, enquanto as medidas subjectivas compreendem sentimentos sobre a vida [...]" (MENDES, 1999, p. 18).

No entanto, neste trabalho optou-se pelos âmbitos de análise por entender que melhor expressam a realidade estudada, dando conta da oferta de bens e serviços urbanos em toda a área territorial de Natal e, portanto, refletindo como se apresenta a qualidade de vida urbana local: aspectos materiais, que estão relacionados com a satisfação das necessidades humanas básicas; aspectos coletivos, que dizem respeito aos serviços básicos e serviços públicos; aspectos objetivos, que são apreendidos através da definição de indicadores de natureza quantitativa (BRASIL, 2004, p. 36).

Assim, essas opções se devem também ao fato de que os indicadores possibilitam a comparação dentro do espaço intraurbano, expressando a realidade comunitária. Ademais, torna-se positivo evitar variáveis subjetivas, uma vez que limitam a comparabilidade.

A partir do amplo levantamento bibliográfico, foram selecionados variáveis e indicadores que tiveram como baliza a concepção de sustentabilidade urbana, observando-se as dimensões social, econômica e ambiental. Desse modo, baseado em Braga (et al., 2003) e SESI (2010), levouse em conta os seguintes critérios: relevância, capacidade da variável em traduzir o fenômeno estudado; disponibilidade, cobertura e atualidade dos dados; capacidade da variável em permitir comparações temporais; estar ligado com as políticas públicas; desagregação; ser de fácil entendimento por parte da sociedade em geral; facilidade em obtenção e atualização dos dados.

Nesse sentido, fez-se a opção de se trabalhar, como unidade geográfica de análise, os dados a partir da divisão da cidade em bairros e em regiões administrativas, ficando possível a comparação entre eles e a criação dos rankings. Além disso, os indicadores utilizados possibilitam a identificação e a espacialização das áreas mais carentes e necessárias de intervenção do poder público.

Para o tratamento estatístico e a análise dos dados levantados foi utilizado como base a metodologia apontada por Pereira et. al (2009, p. 102), empregando-se "a análise tabular e descritiva" das variáveis definidoras da qualidade de vida urbana de Natal. A operacionalização dos dados deu-se no programa informatizado, através de planilha Excel 2007 de Microsoft. Foram criadas diversas planilhas (num total de 27) - uma para cada indicador das quatro variáveis utilizadas para o estabelecimento dos índices temáticos, as quais geraram os índices sintéticos da qualidade de vida urbana do município do Natal.

Desse modo, com base no modelo apresentado nos estudos do Instituto Pólis, de Allmenroeder et al. (2001), de Nahas (2009) e de Figueiredo et al. (2008) buscou-se percorrer os seguintes passos para se determinar o indicador da localidade: i. identificação dos bairros (microrregiões) que fizeram parte do estudo; ii. agrupamento dos bairros que comporiam as regiões administrativas (macrorregiões); iii. separação dos indicadores, por área temática/variáveis; iv. realização do cálculo do índice temático para as micro e as macrorregiões, através da média ponderada entre os índices, por área temática, e os pesos destes (as fórmulas 
apresentadas pelos autores, já descritas anteriormente). Assim, para a identificação e avaliação do IQVU, de Natal (RN), foram definidas quatro variáveis e 23 indicadores, apresentados no Quadro a seguir:

Quadro 1 - Variáveis, indicadores e função relação

\begin{tabular}{|c|c|c|}
\hline VARIÁVEIS & INDICADORES & $\begin{array}{l}\text { Função } \\
\text { Relação }\end{array}$ \\
\hline \multirow{6}{*}{ 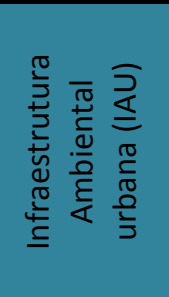 } & Acesso a Coleta do Lixo por serviço (IAU 1) & + \\
\hline & Disponibilidade de Energia Elétrica nos domicílios (IAU 2) & + \\
\hline & Drenagem (IAU 3) & + \\
\hline & Pavimentação (IAU 4) & + \\
\hline & Acesso ao Abastecimento de água (IAU 5) & + \\
\hline & Acesso a Esgotamento sanitário (IAU 6) & + \\
\hline \multirow{7}{*}{ 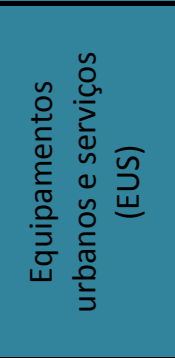 } & Estabelecimentos da área de saúde (EUS 1) & + \\
\hline & Equipamentos desportivos (EUS 2) & + \\
\hline & Equipamentos de segurança pública (EUS 3) & + \\
\hline & Equipamento urbano Praça (EUS 4) & + \\
\hline & Dotação de negócios, comércio e serviços (EUS 5) & + \\
\hline & Número de escolas e creches (EUS 6) & + \\
\hline & Número de linhas de transporte coletivo/alternativos (EUS 7) & + \\
\hline \multirow{7}{*}{ 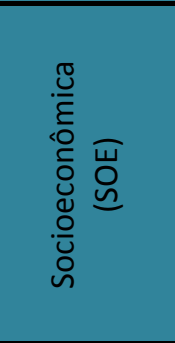 } & População economicamente ativa (SOE 1) & + \\
\hline & Rendimento nominal médio (SOE 2) & + \\
\hline & Rendimento médio per capita (SOE 3) & + \\
\hline & Alfabetização (SOE 4) & + \\
\hline & Densidade demográfica (SOE 5) & - \\
\hline & Áreas subnormais (SOE 6) & - \\
\hline & Domicílios permanentes próprios (SOE 7) & + \\
\hline \multirow{3}{*}{ 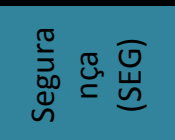 } & Número de homicídios (SEG 1) & - \\
\hline & Número de ocorrências (SEG 2) & - \\
\hline & Número de armas apreendidas (SEG 3) & - \\
\hline
\end{tabular}

Fonte: Adaptado de ARAÚJO (2013, p. 85).

Assim, reforçando o entendimento da qualidade de vida urbana como aquela que atende as necessidades básicas da população por meio da disponibilidade de bens e serviços urbanos, fez-se a opção por trabalhar com as variáveis infraestrutura urbana e sustentabilidade ambiental, equipamentos urbanos e serviços, socioeconômica e segurança por entender que essas são as necessidades materiais básicas para a (re)produção social.

Desse modo, por meio de dados secundários foram calculados os índices, organizados por meio de planilha eletrônica em excel, os quais geraram os níveis de qualidade de vida de Natal, dispostos por bairro.

Para a definição dos índices de cada variável e de cada indicador, utilizou-se o cálculo proposto por Figueiredo et al. (2008, p. 12), o qual "consiste na razão entre a subtração do valor observado do indicador pelo valor mínimo da série do indicador dividido pela subtração do valor máximo pelo valor mínimo da série do indicador", quando o atributo for positivo. Portanto, os indicadores cujos atributos são positivos para a qualidade de vida, ou seja, que contribuam para uma condição sustentada de qualidade de vida, foram calculados os índices por meio desta fórmula: 


$$
\mathrm{I}=\underbrace{\left(\mathrm{X}_{\min }\right)}_{(\mathrm{X} \max -X \operatorname{Xmin})}
$$

Enquanto a equação para o atributo negativo (como por exemplo, número de homicídios, áreas subnormais) passa a ser a razão entre a subtração do valor observado do indicador pelo valor máximo da série do indicador dividido pela subtração do valor máximo pelo valor mínimo da série do indicador. Portanto, os indicadores cujos atributos são negativos para a qualidade de vida, ou seja, que contribua para uma condição insustentada de qualidade de vida, foram calculados os índices por meio da seguinte fórmula:

$$
\mathrm{I}=\frac{(\underline{\mathrm{X} \max -\mathrm{Xi}})}{(\mathrm{X} \max -\mathrm{Xmin})}
$$

Em seguida, para o cálculo do índice final de cada bairro e do IQVU de Natal, utilizou-se a média simples que foi obtida através da soma de todos os índices divididos pela quantidade de índices utilizados (FERREIRA et al., 2008).

Portanto, a partir dos dados secundários, foram calculados os índices, convertidos pela equação acima expressa, estabelecendo-se o intervalo de 0 a 1 para determinar quando o índice apresenta-se muito fraco, fraco, suficiente e bom, conforme a representação do quadro 2.

Quadro 2 - Representação dos níveis do IQVU - gradação de cores*

\begin{tabular}{|c|c|c|}
\hline $\begin{array}{c}\text { Índice } \\
\text { Intervalo entre } 0-1\end{array}$ & Gradação de cores & $\begin{array}{c}\text { Nível de Qualidade } \\
\text { de vida }\end{array}$ \\
\hline $0,000-0,200$ & & Péssima \\
\hline $0,201-0,400$ & & Ruim \\
\hline $0,401-0,600$ & & Regular \\
\hline $0,601-0,800$ & & Boa \\
\hline $0,801-1,000$ & & Muito boa \\
\hline
\end{tabular}

Fonte: ARAÚJO (2013, p. 97).

Portanto, após a transformação dos indicadores em índices a representação gráfica que será utilizada para apresentar o resultado, de cada índice temático, se dará por meio de tabelas e mapas utilizando-se a gradação de cores para expressar Nível de Qualidade de vida de cada bairro.

\section{RESULTADOS E DISCUSSÕES}

Para se chegar ao índice sintético de qualidade de vida urbana de Natal foram levados em consideração variáveis que contemplam as dimensões ambiental, social e econômica.

Ao analisar as variáveis utilizadas para a determinação dos níveis de qualidade de vida urbana de Natal, constata-se que a variável equipamentos urbanos e serviços apresentou os mais baixos índices, sendo considerada como de nível péssimo.

Nesse trabalho, os equipamentos urbanos e serviços considerados para estabelecer os índices dessa variável são: escolas e creches, saúde, equipamentos desportivos, segurança pública, Praça, transportes, comércio e serviços, tanto da esfera pública quanto privada, conforme tabela 1 e análise a seguir. 
Tabela 1 - Equipamentos urbanos e serviços

\begin{tabular}{|l|r|}
\hline \multicolumn{1}{|c|}{$\quad$ Indicadores } & ÍNDICE \\
\hline Estabelecimetos da Área de saúde (EUS 1) & 0,210 \\
\hline Equipamentos desportivos (EUS 2) & 0,242 \\
\hline Equipamentos de segurança pública (EUS 3) & 0,195 \\
\hline Equipamentos urbanos (praça) (EUS 4) & 0,163 \\
\hline Quantidade de negócios, comércio e serviços (EUS 5) & 0,250 \\
\hline Quantidade de escolas e creches (EUS 6) & 0,224 \\
\hline Quantidade de linhas de transportes (EUS 7) & 0,277 \\
\hline ÍNDICE FINAL DA VARIÁVEL & $\mathbf{0 , 2 2 3}$ \\
\hline
\end{tabular}

Fonte: ARAÚJO (2013, p. 131).

Isso reflete a carência, nos bairros, de equipamentos, como: estabelecimentos da área de saúde; equipamentos desportivos; equipamentos de segurança pública; equipamento urbano praça; dotação de negócios, comércio e serviços; número de escolas e creches e número de linhas de transporte coletivo/alternativos. O índice equipamentos urbanos e serviços contempla a média e a análise de todos os indicadores que compõem essa variável. Através de uma média simples, chegou-se ao resultado desse índice.

Levando-se em consideração o índice final dessa variável, verifica-se que nenhum bairro de Natal obteve índice cujo nível é considerado como muito bom. Ao contrário, mais de $90 \%$ dos bairros apresentaram índices considerados como péssimos ou ruins.

Na variável infraestrutura ambiental urbana, em que a dimensão é ambiental, a maior parte dos bairros de Natal obteve um índice considerado como bom ou muito bom. Através de uma média simples, chegou-se ao resultado desse índice.

O índice obtido para Natal, dessa variável, foi calculado a partir da média simples entre os índices encontrados nos indicadores dos bairros, comparando-os entre si. Leva-se em consideração, para a obtenção do índice, o que foi proposto pela Agenda Habitat (2003) em se tratando da adequação habitacional. Assim, chegou-se ao resultado que a cidade apresenta, nessa variável, um nível bom de qualidade de vida, contemplando os indicadores Acesso a Coleta do Lixo por serviço, Disponibilidade de Energia Elétrica nos domicílios, Drenagem, existência de Pavimentação, Acesso ao Abastecimento de água, Acesso a Esgotamento sanitário, conforme tabela e análise a seguir.

Tabela 2 - Infraestrutura ambiental urbana

\begin{tabular}{|c|c|}
\hline Indicadores & ÍNDICE \\
\hline Destino de lixo (IAU 1) & 0,722 \\
\hline Energia elétrica (IAU 2) & 0,901 \\
\hline Drenagem (IAU 3) & 0,762 \\
\hline Pavimentação (IAU 4) & 0,774 \\
\hline Abastecimento de água (IAU 5) & 0,750 \\
\hline Esgotamento sanitário (IAU 6) & 0,488 \\
\hline ÍNDICE FINAL & 0,733 \\
\hline
\end{tabular}

Fonte: ARAÚJO (2013, p. 111).

Os bairros de Candelária e Planalto obtiveram os índices mais baixos, enquanto os bairros de Areia Preta, Barro Vermelho e Cidade da Esperança ficaram com os índices mais elevados. No que se referem às zonas administrativas de Natal, os piores índices foram apresentados pelos 
bairros localizados na zona administrativa norte, tais como: Salinas, Redinha, Lagoa Azul, Nossa Senhora da Apresentação e Pajuçara.

Os bairros da zona administrativa leste apresentaram os maiores índices nessa variável, com destaque para os bairros de Areia Preta e Barro Vermelho, que, em dois indicadores, apresentaram os maiores índices. Esse resultado pode ser justificado pelo fato de o núcleo urbano de Natal ter sido iniciado nessa zona administrativa. Isso justifica também o fato de que, durante muito tempo, os planos urbanísticos foram voltados para esse núcleo original da cidade.

Por outro lado, pode-se constatar que as áreas de expansão urbana, zona norte, oeste e mesmo da sul apresentam fragilidade quanto à infraestrutura urbana, o que pode comprometer a qualidade do ambiente e, portanto, da vida urbana de Natal.

Depreende-se que o índice obtido nessa variável pode ser justificado por se constituir de indicadores cujo investimento depende quase exclusivamente do Estado, sendo condições básicas e essenciais para a qualidade ambiental urbana e, por conseguinte, para a qualidade de vida da população.

Na variável socioeconômica, sete indicadores estão integrados, em que foram calculados e analisados os índices, tais como: rendimento nominal médio, rendimento nominal per-capita, população economicamente ativa, alfabetização, densidade demográfica, condição de ocupação do domicílio, aglomerados subnormais (ver Tabela 3).

Tabela 3 - Variável socioeconômica

\begin{tabular}{ll}
\hline \multicolumn{1}{c}{ Indicadores } & Índice \\
\hline População economicamente ativa (SOE 1) & 0,376 \\
\hline Rendimento nominal médio (SOE 2) & 0,265 \\
\hline Rendimento médio per capita (SOE 3) & 0,726 \\
\hline Alfabetização (SOE 4) & 0,702 \\
\hline Densidade demográfica (SOE 5) & 0,535 \\
\hline Áreas subnormais (SOE 6) & 0,810 \\
\hline Domicílios permanentes (SOE 7) & 0,388 \\
\hline íNDICE FINAL & $\mathbf{0 , 5 4 6}$ \\
\hline
\end{tabular}

Fonte: ARAÚJO (2013, p. 149).

O índice sintético dessa variável apresenta um nível considerado como regular, o que evidencia uma exclusão socioeconômica da população, refletida na qualidade de vida urbana, uma vez que a menor condição socioeconômica implica também dificuldade de acesso aos bens e serviços da infraestrutura urbana.

Dos indicadores analisados, somente um (indicador quantidade de Áreas subnormais) apresenta um nível considerado como muito bom. O bairro de Felipe Camarão obteve o mais baixo índice na variável socioeconômica, sendo considerada como de nível péssimo. Já o bairro de Tirol, apresentou o maior índice com nível considerado como muito bom. Os piores índices foram obtidos pelos bairros de Felipe Camarão e Mãe Luiza, enquanto os maiores índices foram obtidos pelos bairros de Tirol e Candelária.

No índice final da variável segurança, a maior parte dos bairros de Natal obtiveram índices considerados como muito bom ou bom. Observa-se que somente um bairro obteve índice igual a 1,000, o que evidencia que a violência e a insegurança expõe a todos indiscriminadamente. 
Tabela 4 - Variável Segurança

\begin{tabular}{lc}
\hline \multicolumn{1}{c}{ Indicadores } & Índice \\
\hline Número de homicídios (SEG 1) & 0,756 \\
\hline Número de ocorrências (SEG 2) & 0,626 \\
\hline Número de armas apreendidas (SEG 3) & 0,764 \\
\hline ÍNDICE FINAL & $\mathbf{0 , 7 1 4}$ \\
\hline
\end{tabular}

Dois bairros, Lagoa Azul e Nossa Senhora da Apresentação, obtiveram índices considerados como de nível ruim, comprovando serem os mais violentos do município. Isso evidencia a segregação socioespacial na qual esses bairros estão sujeitos. No entanto, quando se observam os índices apresentados no indicador equipamentos de segurança, os referidos bairros obtiveram índices considerados como péssimos, o que também pode justificar a realidade apresentada na variável segurança.

Demonstra-se que somente o bairro de Salinas obteve índices máximos em todos os indicadores, podendo indicar ser o bairro mais seguro de Natal. Quando se observa o índice final, ou seja, o IQVU de Natal por bairros (contemplando todas as variáveis), constata-se que os Bairros da Zona Administrativa Norte ficaram com os índices mais baixos, o que evidencia que os bairros mais afastados das áreas centrais da cidade não são bem servidos de infraestrutura básica necessária à qualidade de vida urbana. Além disso, fica evidente também que a exclusão social implica, consequentemente, a exclusão espacial.

Observa-se que os bairros da Zona Administrativa Sul obtiveram o melhor índice, com destaque para o bairro de Lagoa Nova, que obteve o maior índice nessa zona administrativa. Na sequência, a zona administrativa leste ficou em segundo lugar, com destaque para os bairros de Tirol e Barro Vermelho, os quais figuram entre os três primeiros lugares no ranking da qualidade de vida de Natal.

A tabela 5, a seguir, mostra o índice final da qualidade de vida de Natal, no qual foi elaborado o ranking dos bairros de Natal, em ordem decrescente, enfatizando os níveis obtidos por cada bairro.

Tabela 5 - Ranking dos bairros Índice de Qualidade de Vida Urbana de Natal-RN

\begin{tabular}{|c|c|c|}
\hline Classificação & Nome do Bairro & $\begin{array}{l}\text { ÍNDICE } \\
\text { FINAL }\end{array}$ \\
\hline 10 & Tirol & 0,684 \\
\hline 20 & Lagoa Nova & 0,677 \\
\hline 3음 & Barro Vermelho & 0,668 \\
\hline 49 & Pitimbu & 0,650 \\
\hline 50 & Areia Preta & 0,621 \\
\hline 60 & Neópolis & 0,618 \\
\hline 70 & Lagoa Seca & 0,607 \\
\hline 80 & N.S. de Nazaré & 0,591 \\
\hline 9o & Potengi & 0,590 \\
\hline 109 & Cidade da Esperança & 0,588 \\
\hline 11 은 & Petrópolis & 0,587 \\
\hline 120 & Alecrim & 0,585 \\
\hline 13 은 & Santos Reis & 0,584 \\
\hline 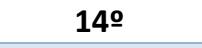 & Capim Macio & 0,575 \\
\hline 150 & Nordeste & 0,572 \\
\hline
\end{tabular}




\begin{tabular}{|c|c|c|}
\hline 160 & Ribeira & 0,571 \\
\hline 170 & Praia do Meio & 0,566 \\
\hline $18^{\circ}$ & Nova Descoberta & 0,563 \\
\hline 199 & Ponta Negra & 0,562 \\
\hline $20 \%$ & Rocas & 0,550 \\
\hline 210 & Candelária & 0,541 \\
\hline 220 & Dix-Sept Rosado & 0,533 \\
\hline 23요 & Quintas & 0,529 \\
\hline 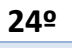 & Cidade Alta & 0,521 \\
\hline 250 & Pajuçara & 0,496 \\
\hline 260 & Cidade Nova & 0,481 \\
\hline 270 & Salinas & 0,462 \\
\hline 280 & Bom Pastor & 0,458 \\
\hline 290 & Mãe Luiza & 0,455 \\
\hline 30 요 & Redinha & 0,430 \\
\hline 310 & Lagoa Azul & 0,428 \\
\hline $32 \circ$ & Guarapes & 0,426 \\
\hline $33 \%$ & Igapó & 0,418 \\
\hline 349 & Planalto & 0,401 \\
\hline $35 \circ$ & Felipe Camarão & 0,378 \\
\hline 360 & N.S. da Apresentação & 0,355 \\
\hline
\end{tabular}

Fonte: ARAúJO (2013, p. 173).

Ao observar o nível alcançado pelos bairros que apresentam os índices mais baixos e observando-se, também, os níveis obtidos pelos bairros que expressaram os índices mais altos, constata-se que as áreas de expansão urbana de Natal exibiram os piores índices de qualidade de vida urbana, conforme observa-se na figura a seguir.

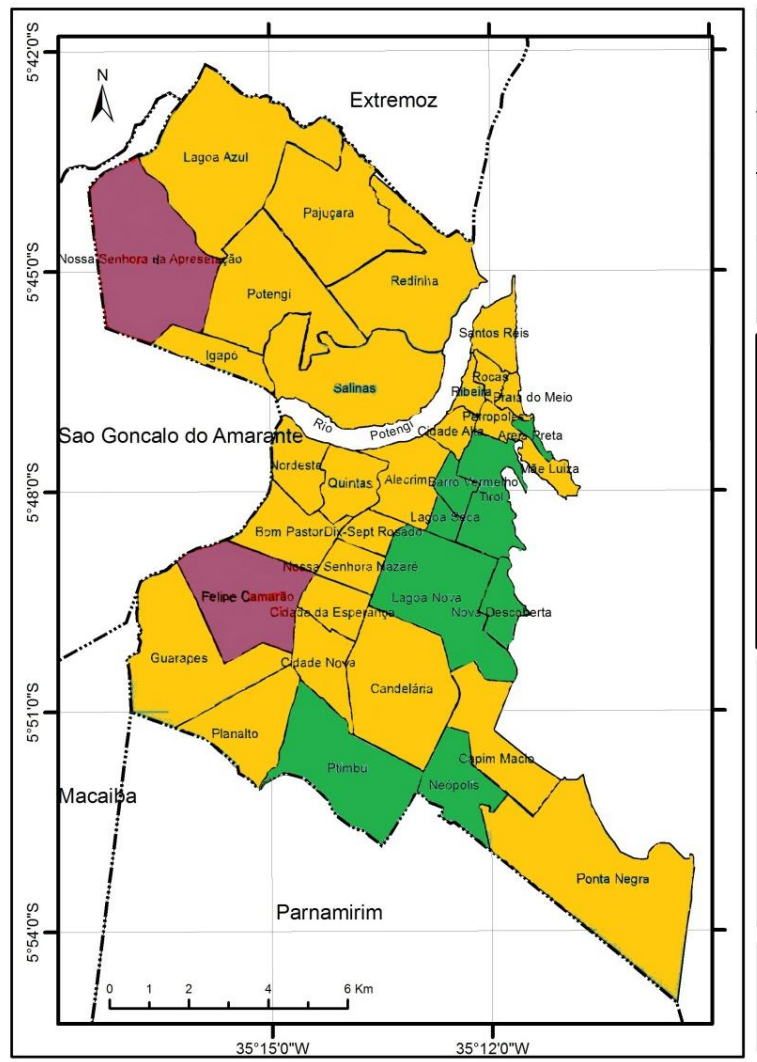

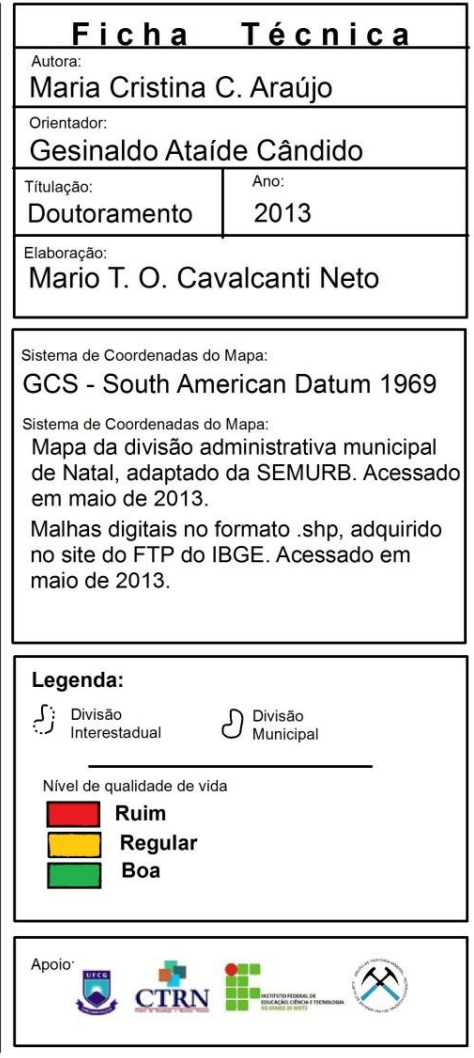

Figura 2 - Localização espacial do IQVU de Natal-RN por bairros 
As áreas mais próximas ao centro da cidade são mais dotadas de equipamentos e serviços urbanos; as áreas mais afastadas são carentes de investimento e de políticas públicas e privadas, refletindo, pois, a vulnerabilidade e a exclusão socioespacial a que essa parte da cidade está exposta.

\section{CONSIDERAÇÕES FINAIS}

A partir das análises empreendidas, conclui-se que a urbanização e a consequente expansão urbana não têm sido acompanhadas por investimentos em equipamentos urbanos, ao menos na mesma proporção. Assim, a equidade de acesso (ou a falta dela), a exclusão social e espacial vêm à tona, tornando o ambiente urbano incompatível com a ideia recorrente de sustentabilidade urbana e, portanto, de qualidade de vida urbana.

No transcorrer do trabalho, evidenciou-se a construção de indicadores (sociais, econômicos e ambientais) como forma de medir a qualidade de vida urbana de Natal, dentro da perspectiva da sustentabilidade urbana.

Nesse sentido, nas áreas onde ocorreu a recente expansão urbana de Natal-RN encontram-se os piores índices de qualidade de vida urbana. Os resultados alcançados evidenciam, também, uma cidade segregada, injusta e excludente, cujo índice de qualidade de vida urbana tem sido considerado regular.

Por fim, conclui-se que a sustentabilidade urbana não condiz com uma cidade socioespacialmente segregada e injusta, onde os bens de serviços urbanos não são distribuídos de forma igual. Dessa maneira, a qualidade de vida urbana só será conseguida de forma satisfatória, quando a ideia de "justiça" for associada à acessibilidade e quando o modelo de urbanização preconize uma cidade compacta, descentralizada e policêntrica, ao facilitar o acesso aos bens e serviços urbanos.

Destaca-se a relevância deste estudo, porquanto pode contribuir com a sociedade em geral e com a gestão pública municipal ao mensurar e estabelecer os níveis espaciais de oferta de serviços e recursos urbanos que serão de extrema importância para a identificação e o monitoramento da qualidade de vida urbana de Natal-RN.

As variáveis e os indicadores, aqui trabalhados, refletem uma opção teórico-metodológica que não esgota os estudos sobre qualidade de vida urbana, podendo o estudo ser complementado, em outro momento, com variáveis e indicadores que possam ser mensurados e avaliados a partir de aspectos subjetivos e dados qualitativos.

\section{REFERÊNCIAS}

1. ACSELRAD, Henri. Desregulamentação, contradições espaciais e sustentabilidade urbana. Revista paranaense de desenvolvimento, Curitiba, n.107, p.25-38, jul./dez. 2004.

2. ADORNO, Sérgio. Exclusão socioeconômica e violência urbana. Sociologias, Porto Alegre, ano 4, n 8, jul/dez, p. 84-135, 2002.

3. AGENDA HABITAT PARA MUNICÍPIOS. Plano global de ação: estratégias para a implementação. B. Moradia adequada para todos. 2003. Disponível em: 
<http://www.ibam.org.br/publique/cgi/cgilua.exe/sys/start.htm?sid=96\&infoid=458>. Acesso em: 10 jul. 2012.

4. ALLMENROEDER, Leonardo Bullos; SARMENTO, Robson; SERAFIM, Alexandre José; ZORZAL, Fábio Márcio Bisi. Indicadores de qualidade de vida urbana municipal (o caso do município de Vitória). In: Associação Brasileira de Engenharia Sanitária e Ambiental; AIDIS. Saneamento ambiental: desafio para o Século 21. Rio de Janeiro, ABES, 2001. p.1-12.

5. ARAÚJO, Maria Cristina Cavalcanti. Avaliação do nível de qualidade de vida urbana: um estudo exploratório a partir do fenômeno da expansão urbana e oferta de serviço e recursos urbanos no município do Natal/RN / Maria Cristina Cavalcanti Araújo. - 2013. 197 f. : il. Tese (Doutorado) - Universidade Federal de Campina Grande, Programa de Pós-Graduação em Recursos Naturais, Campina Grande - PB, 2013.

6. BRAGA, Tania Moreira et al. Índices de sustentabilidade municipal: o desafio de mensurar. Belo Horizonte: UFMG/Cedeplar, 2003. 22p. (Texto para discussão; 225).

7. BRASIL. Ministério do Meio Ambiente. AGENDA 21 Brasileira: ações prioritárias / Comissão de Políticas de Desenvolvimento Sustentável e da Agenda 21 Nacional. 2. ed. Brasília, DF. 2004. $158 \mathrm{p}$.

8. CMMAD - COMISSÃO MUNDIAL SOBRE MEIO AMBIENTE E DESENVOLVIMENTO. NosSO futuro comum. 2a ed. Tradução de Our common future. 1a ed. 1988. Rio de Janeiro: Editora da Fundação Getúlio Vargas, 1988.

9. FERREIRA, Ângela Lúcia de Araújo; ATAÍDE, Ruth Maria da Costa; BORGES, Jennifer dos Santos. Conflitos sócio-espaciais em áreas protegidas de Natal (RN): limites e desafios para uma nova prática urbanística. Anais da II ANPPAS, 2004. II Encontro da ANPPAS, Indaiatuba SP; BR; Meio Digital. Disponível em <http://www.anppas.org.br/encontro_anual/ encontro2/GT/GT14/angela_ferreira.pdf>. Acesso em: 20 nov. 2007.

10. FIGUEIREDO, Alice Sueiro de [et al.]. Índice de qualidade de vida urbana de Campo GrandeMS. Campo Grande: PLANURB, 2008. 31 p.

11. GUIMARÃES, Mauro. Sustentabilidade e Educação Ambiental. In: CUNHA, Sandra Baptista da; GUERRA, Antônio José Teixeira (Orgs.). A questão ambiental: diferentes abordagens. 4a ed. Rio de Janeiro: Bertrand Brasil, 2008. p.81-105.

12. HERCULANO, Selene. A qualidade de vida e seus indicadores. In: Ambiente \& Sociedade. Ano I, no 2, 1ㅇs semestre/1998.

13. IBGE. Instituto de Geografia e Estatística. Censo 2010. Aglomerados subnormais: primeiros resultados. Rio de Janeiro, RJ: 2010.

14. IBGE. Instituto Brasileiro de Geografia e Estatística. Censo 2010: população do Brasil é de 190.732.694 pessoas. 29 nov. 2010. Disponível em < http://www.ibge.gov.br/home/presi dencia/noticias/noticia_visualiza.php?id_noticia=1766>. Acesso: 21 mar. 2011. IBGE: 2010d.

15. IBGE. Instituto Brasileiro de Geografia e Estatística. Censo Demográfico 2010 Resultados Preliminares do Universo Conceitos e Definições - Tabelas Adicionais. Rio de Janeiro, 2011a.

16. IBGE. Instituto de Geografia e Estatística. Censo Demográfico 2010. Disponível em < http://www.ibge.gov.br/cidadesat/topwindow.htm?1>. Acesso em: 22 jun. 2011 b.

17. JOFRÉ, Mario Torre. Índice de Sostenibilidad Urbana: una propuesta para la ciudad Compleja. Revista Digital Universitaria. 10 de jul. 2009. Vol. 10 Número 7. ISSN: 1067-6079. Disponível 
em < http://www.revista.unam.mx/vol.10/num7/art44/art44.pdf>. Acesso em 10 ago. 2012.

18. LEITE, Sandrina Martins. Avaliação da Qualidade da Vida Urbana - O Caso do Concelho de Amarante. Tese de mestrado. Universidade de Trás-os-Montes e Alto Douro. Departamento de engenharias. Divisão de engenharia civil. Portugal, 2009.

19. MARTINS, Maria de Fátima; CÂNDIDO, Gesinaldo Ataíde. Índices de desenvolvimento sustentável para localidades: uma proposta metodológica de construção e análise. In: CÂNDIDO, Gesinaldo Ataíde. Desenvolvimento sustentável e sistemas de indicadores de sustentabilidade: formas de aplicações em contextos geográficos diversos e contingências específicas. Campina Grande-PB: Ed. UFCG, 2010.

20. MORATO, Rúbia Gomes; KAWAKUBO, Fernando Shinji Kawakubo; MARTINES, Roberto Martines; FERREIRA, Ricardo Vicente Ferreira; LUCHIARIA, Ailton. Mapeamento da Qualidade de Vida Urbana no Município de Osasco/SP. In: Anais do III Encontro da Associação Nacional de Pós Graduação e Pesquisa em Ambiente e Sociedade. Brasília - Distrito Federal - Brasil, 2006.

21. MUMFORD, Lewis. A Cidade na História - suas origens, transformações e perspectivas. Tradução de Neil R. da Siva. Martis Fontes Editora, São Paulo, 1998.

22. NAHAS, Maria Inês. Indicadores intra-urbanos como instrumentos de gestão da qualidade de vida urbana em grandes cidades: discussão teórico-metodológica. In: Planejamento público e indicadores sociais. Curitiba, 2005.

23. NAHAS, Maria Inês Pedrosa; PEREIRA, Maria Aparecida Machado; ESTEVES, Otávio de Avelar; GONÇALVES, Éber. Metodologia de construção do índice de qualidade de vida urbana dos municípios brasileiros (IQVU-BR). In: XV Encontro Nacional de Estudos Populacionais da Associação Brasileira de Estudos Populacionais, 2006. Disponível em: <www.abep.nepo .unicamp.br/encontro2006/.../ABEP2006_420.pdf>. Acesso em: 15 mar. 2011.

24. NATAL. SEMURB - Secretaria Municipal de Meio Ambiente e Urbanismo. Anuário Natal 20112012, Natal (RN): SEMURB, 2012. 402 p.

25. NATAL. Secretaria Municipal de Planejamento, Orçamento e Finanças. Déficit habitacional em Natal: um estudo por bairro. Natal-RN: Prefeitura do Natal, 2006.

26. OLIVEIRA, Isabel Cristina Eiras. Arquitetura e urbanismo nas cidades sustentáveis. In: Livro Exercício Profissional e Cidades Sustentáveis, 61으 Semana Oficial da Engenharia, da Arquitetura e da Agronomia - SOEAA e 5o Congresso Nacional dos Profissionais - CNP. CONFEA, Maranhão, 2004. p. 169-181.

27. ROGERS, Richard. Cidades para um pequeno planeta. Tradução Anita Regina Di Marco. Editorial Gustavo Gili, SL. Barcelona, Espanha, 2008.

28. ROLNIK, Raquel. Para morar e para criar. Entrevista a Efêmero concreto. Mar. De 2012. Disponível em http://efemeroconcreto.com.br/?p=40. Acesso em 10 dez. 2012.

29. ROSSETTO, Adriana Marques. Proposta de um Sistema integrado de Gestão do Ambiente Urbano (SIGAU) para o desenvolvimento sustentável de cidades. Tese apresentada ao Programa de Pós-Graduação em Engenharia de Produção (PPGEP) da Universidade Federal de Santa Catarina (UFSC). Florianópolis: 2003.

30. SACHS, Ignacy. Estratégias de transição para o século XXI. In: BURSZTYN, Marcel (Org.). Para pensar o desenvolvimento sustentável. São Paulo: Brasiliense, 1993. p. 29-56. 
31. SANTOS, Milton. A Natureza do Espaço: Técnica e Tempo, Razão e Emoção / Milton Santos. 4. ed. 2. reimpr. - São Paulo: Editora da Universidade de São Paulo, 2006. Coleção Milton Santos, 1.

32. SESI. SERVIÇO SOCIAL DA INDÚSTRIA. Construção e Análise de Indicadores. Serviço Social da Indústria. Departamento Regional do Estado do Paraná. Observatório Regional Base de Indicadores de Sustentabilidade. - Curitiba: [s.n.], 2010. 108 p. : il. ; 21 cm.

33. TRIGUEIRO, A. Mundo sustentável: abrindo espaço na mídia para um planeta em transformação. São Paulo: Globo, 2005. 